\title{
Zika Gamification: Mobile Application for Endemic Disease Control Agents Training
}

\author{
Mateus O. Fonseca ${ }^{1}$, Gilson P. dos Santos Júnior ${ }^{1}$, Lauro B. Fontes ${ }^{1}$, \\ Thiers Garretti R. Sousa ${ }^{1}$
}

\author{
${ }^{1}$ Coordenadoria do Bacharelado de Sistemas de Informação (CBSI) \\ Instituto Federal de Educação, Ciência e Tecnologia de Sergipe (IFS) - Campus Lagarto \\ Rua Cauby, $\mathrm{n}^{\circ}$ 523. Bairro Jardim Campo Novo - Lagarto - SE - Brazil. \\ \{gilson.pereira, lauro.fontes, thiers.sousa\} aifs.edu.br
}

\begin{abstract}
The Endemic Disease Control Agents (ECAs) are the professionals responsible for preventing and fighting the Aedes Aegypti mosquito in the communities. These professionals must be trained by the qualification training course of ECAs. However, they report to the inefficiency in their training, mainly, to a low investments, educational events and the sharing of knowledge. This article presents Zika Gamification, a mobile application that is used to help in the training of ECAs in the municipality of Lagarto, Sergipe. The experiment was taken with 17 ECAs from the region showed that for more than 59\% of the interviewed, the technical and pedagogical aspects were reached with the application.
\end{abstract}

Resumo. Os Agentes de Combate à Endemias (ACEs) são os profissionais responsáveis pela prevenção e pelo combate ao mosquito Aedes Aegypti nas comunidades. Estes profissionais devem ser capacitados pelo curso de formação profissional de ACEs. Entretanto, os agentes apontam a ineficiência na sua formação, principalmente, devido a falta de investimentos, de eventos educativos e do compartilhamento do saber. Este artigo apresenta o Zika Gamification, uma aplicação móvel gamificada para auxiliar no treinamento dos ACEs do município de Lagarto, Sergipe. O experimento realizado com 17 ACEs da região demonstrou que para mais de 59\% do participantes os aspectos técnicos e pedagógicos foram atingidos com a aplicação.

\section{Introdução}

Um dos grandes desafios do Brasil na área da saúde pública é o combate ao mosquito Aedes Aegypti. A rápida proliferação desse mosquito, capaz de se reproduzir em pequenos volumes de água parada, aumenta o número de casos da Dengue, da febre Chikungunya e do vírus Zika, principalmente no verão. É justamente nesta época que os Agentes de Combate à Endemias (ACEs) são mais atuantes.

Os ACEs são profissionais da saúde que trabalham na prevenção e no combate à endemias nas comunidades, bem como executam ações educativas com a população. De acordo com [Torres 2009], os ACEs são responsáveis por: vistoriar residências, depósitos, terrenos baldios e estabelecimentos comerciais em busca de focos endêmicos; inspecionar ralos, caixas d'água, calhas e telhados; aplicar larvicidas e inseticidas; e orientar a população quanto à prevenção e tratamento de doenças infecciosas. 
Antes de iniciarem as atividades, os ACEs são submetidos ao curso de formação profissional, conforme estabelecido nas "Diretrizes e Orientações para o Programa de Qualificação dos Agentes de Combate a Endemias e demais Agentes que atuam na Vigilância em Saúde" [Ministério da Saúde 2011].

Embora existam diretrizes e orientações para capacitação, os ACEs relatam a falta de: investimentos no processo de qualificação; espaços físicos para encontros e eventos educativos; e compartilhamento do saber por parte dos coordenadores. Estes, por sua vez, apontam rotatividade de pessoal e falta de tempo decorrente da sobrecarga de trabalho como os motivadores para as fragilidades do treinamento [Fraga and Monteiro 2014]. Independente dos motivos, os relatos apontam a falta ou a ineficiência na formação dos Agentes de Combate à Endemias, o que afeta diretamente suas atribuições, dentre elas, o combate ao mosquito Aedes Aegypti.

Como alternativas para auxiliar o combate do mosquito Aedes Aegypti, alguns trabalhos têm focado no uso da gamificação como, por exemplo, [Oliveira Júnior et al. 2016], [Oliveira et al. 2016] e [Quintão 2016]. No entanto, nenhuma destas propostas visam auxiliar ou aprimorar a capacitação dos profissionais responsáveis por executar ações de combate ao vetor.

A gamificação consiste no uso de mecânica, ideias e estética de games, em contextos de não game, com intuito de engajar pessoas, motivar ações, promover o aprendizado e solucionar problemas [Kapp 2012]. Elementos dos jogos como: o feedback imediato e frequente, a motivação através da competição, o progresso visual por meio de emblemas, a liberdade de falhar, reiniciar e tentar novamente, aumentam o engajamento do aluno e o ajuda a aprender [Kapp 2012].

É neste contexto que o presente trabalho se propôs a desenvolver uma aplicação móvel gamificada, denominada Zika Gamification, para auxiliar no treinamento dos Agentes de Combate à Endemias do município de Lagarto, em Sergipe. Para tanto, foi necessário conhecer a forma de treinamento dos agentes da região e projetar o curso de formação dos agentes utilizando mecânicas, dinâmicas e técnicas da gamificação adequadas ao contexto de combate à endemias.

Com o Zika Gamification é possível mensurar o nível de conhecimento teórico dos Agentes de Combate à Endemias, bem como motivá-los a praticar os conceitos, reforçando o saber sobre alguns desses conceitos, relembrando outros e aprendendo novos. Além disso, a base de questões do treinamento é flexível e expansível, possibilitando a adição de novos assuntos e questões.

O restante do trabalho está organizado em cinco seções. A Seção 2 apresenta os principais trabalhos relacionados. Já a Seção 3 detalha a aplicação Zika Gamification. A Seção 4 descreve metodologicamente a avaliação da aplicação, enquanto que na Seção 5 são discutidos os resultados do estudo. Por fim, a Seção 6 conclui o documento, apresentando suas limitações e algumas opções de trabalhos futuros.

\section{Trabalhos Relacionados}

A gamificação vem sendo utilizada em aplicações educativas e de combate ao mosquito Aedes Aegypti nos últimos anos, a exemplo dos trabalhos de [Oliveira Júnior et al. 2016], [Quintão 2016] e [Oliveira et al. 2016]. 
[Oliveira Júnior et al. 2016] desenvolveram um jogo sério, educativo, para o combate à proliferação dos criadouros do mosquito Aedes Aegypti, o Aedes Game. Neste jogo, os jogadores respondem 20 questões de múltiplas alternativas e a cada resposta correta, o mosquito é acertado por uma raquete elétrica e foge para um novo cenário. Ao final, o jogador visualiza o seu nível de experiência e a quantidade de estrelas obtidas. De acordo com os autores, este jogo é considerado um Social Gamefication visto a relevância do conteúdo existente.

Por sua vez, [Quintão 2016] projetou, também, um jogo sério e educativo, com o intuito de conscientizar as pessoas sobre a importância do combate a dengue, o X-Dengue. Entretanto, neste, o jogador deve eliminar os focos de dengue, proteger os amigos contra o ataque dos mosquitos, impedir a oviposição. O jogo apresenta mecanismos de gamificação como o sistema de recompensas, de pontuação, de ranking e de troca de moeda para customização.

Já [Oliveira et al. 2016] propuseram o "AedesBusters" uma aplicação móvel com uso de gamificação e Crowdsourcing, para facilitar a denúncia de focos de Aedes Aegypti e casos de doenças às Vigilâncias Ambiental e Epidemiológica de Campina Grande, na Paraíba. A gamificação foi utilizada pelos autores para incentivar as denúncias em troca de recompensas, conquistas e prestígio através do ranking.

\section{Zika Gamification}

O Zika Gamification é uma aplicação gamificada com perguntas de múltiplas escolha (quiz), apresentadas através de três tipos de hipermídias (imagem, texto e vídeo), organizadas em módulos e etapas que abordam temas como: a história do Aedes Aegypti no Brasil, o ciclo de vida do mosquito, as doenças transmitidas por este vetor, as atribuições do ACEs, o Levantamento de Índice Rápido do Aedes aegypti (LIRAa ${ }^{1}$ ) e o Programa Nacional de Controle da Dengue (PNCD).

A dinâmica do jogo possibilita a atribuição de pontos de experiência, de emblemas e do reconhecimento de níveis do Agente de Combate à Endemias a medida que este evolui no treinamento. A qualquer momento, o jogador pode visualizar o seu status ou comparar seu desempenho com os demais agentes através do sistema de ranking. $\mathrm{O}$ ranking foi adicionado como uma estratégia extrínseca de motivação social, semelhante ao utilizado por [Oliveira et al. 2016], no qual se espera que a busca pelo reconhecimento público favoreça e incentive o aprendizado. O feedback ao jogador é imediato por cada etapa concluída, favorecendo o aprendizado dos conceitos abordados.

A aplicação foi construída para plataforma Android 6.0 Marshmallow, utilizando a ferramenta Android Studio e o banco de dados Firebase. A arquitetura da aplicações foi projetada para permitir a sua expansão e inclusão de novos módulos, etapas e questões. Atualmente, o jogo possui 50 questões organizadas em 4 módulos, sendo que o módulo 1 e 4 possuem 2 etapas, enquanto os módulos 2 e 3 são constituídos por 3 etapas.

\subsection{Interface da aplicação}

Ao iniciar a aplicação é solicitada a autenticação do jogador previamente cadastrado. Uma vez autenticado, a aplicação apresenta à tela de "Boas vindas" (Figura 1(a)), nela o

\footnotetext{
${ }^{1}$ O LIRAa é uma metodologia para mapeamento dos locais com altos índices de infestação do mosquito Aedes aegypti.
} 
jogador terá de escolher o botão de Treinamento, Status ou Ranking.

Caso selecione a opção de treinamento, na tela de Principal, o jogador visualizará os módulos do treinamento (Figura 1(b)). Ao selecionar o módulo, serão exibidas as etapas que o compõe (Figura 1(c)).

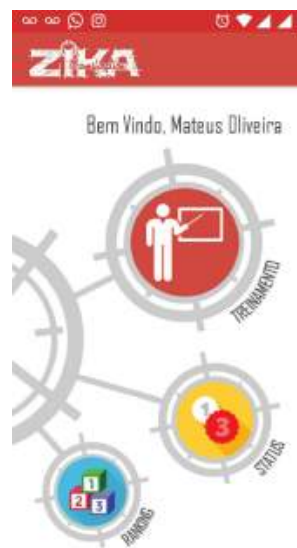

(a) Principal
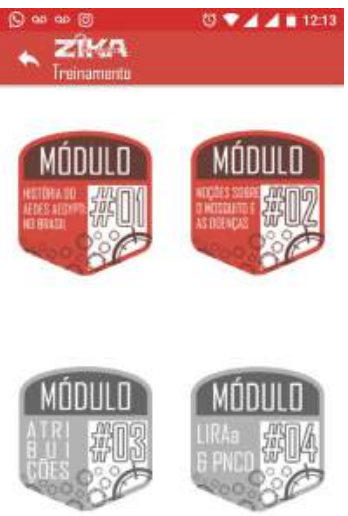

(b) Módulos

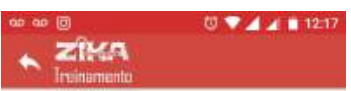

\section{a}

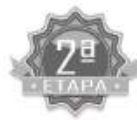

Figura 1. Telas de Treinamento do Zika Gamification.

As etapas são constituídas por questões objetivas sobre o curso de formação de ACEs. As questões podem ser exclusivamente textuais, possuir imagens (Figura 2(a)) ou vídeos (Figura 2(b)). Nas questões com vídeos, o Zika Gamification abre uma nova janela, com o intuito de melhorar a experiência do usuário durante a visualização (Figura 2(c)).

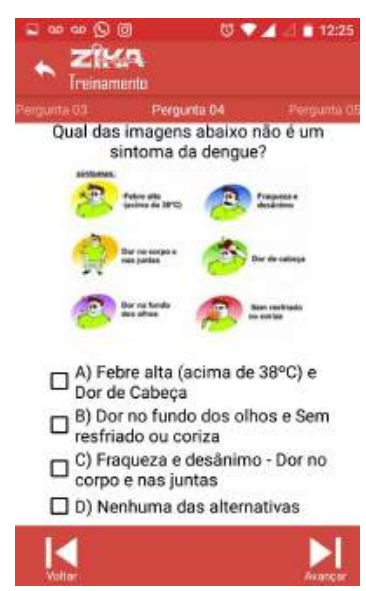

(a) Questões com imagens

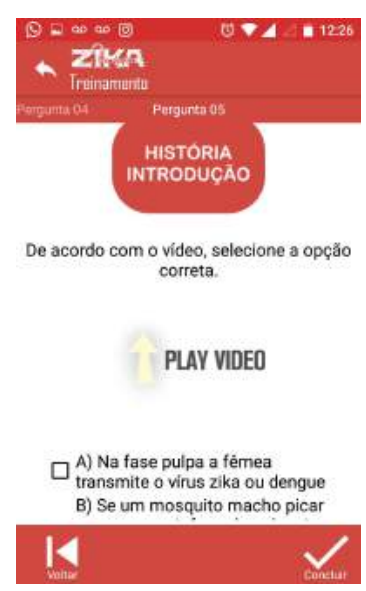

(b) Questões com vídeo.

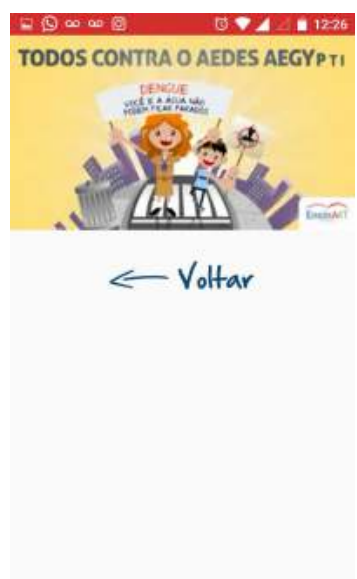

(c) Visualização do vídeo.

Figura 2. Apresentação das Questões.

Ao conquistar a etapa do módulo, isto é, ao responder todas as questões da etapa atual, a aplicação exibe à medalha conquistada pelo jogador, o total de questões e acertos, conforme apresentado na Figura 3(a). A medalha obtida pode ser: bronze, quando ocorreu apenas 1 acerto; prata, ao obter 2 ou 3 acertos; ouro, quando 4 ou mais questões 
foram respondidas corretamente. Uma vez conquistada com perfeição todas as etapas dos módulos, o jogador estará apto a exercer as atividades em campo, visto que conhecerá o conteúdo do curso de formação.

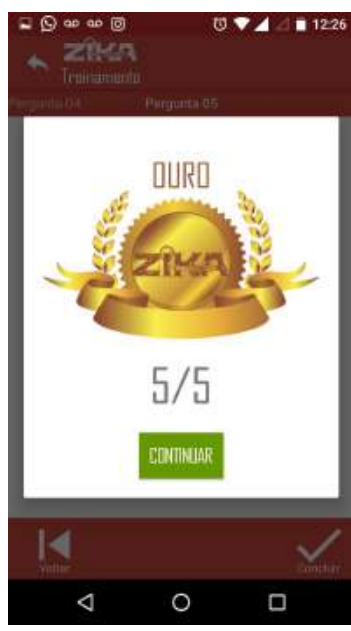

(a) Resultado da etapa.

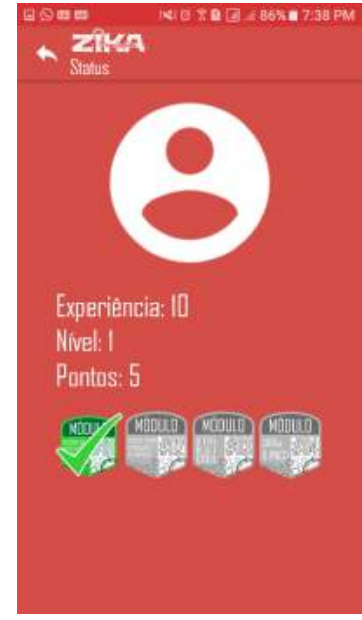

(b) Status do jogador.

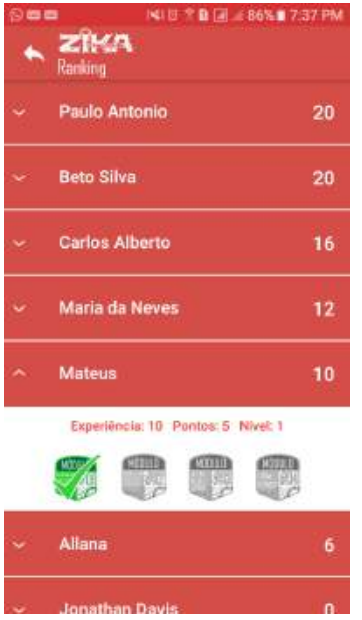

(c) Ranking do treinamento.

Figura 3. Telas de desempenho do jogador.

A qualquer momento o jogador pode acompanhar seu desempenho individual, visualizando a experiência obtida, o nível alcançado, o total de pontos e os módulos conquistados, conforme Figura 3(b). É possível ainda comparar o seu desempenho com os demais jogadores na tela de ranking (Figura 3(c)).

\section{Materiais e Métodos}

O Zika Gamification foi avaliado segundo critérios estabelecidos no instrumento construído por [Rodrigues 2014], baseado na literatura de [Gladcheff 2001] e [Savi et al. 2011]. Este instrumento é composto por questões que avaliam os aspectos técnicos e pedagógicos, além da opinião do aluno sobre o jogo. Diferente da abordagem dos autores, neste trabalho todos os critérios foram avaliados por Agentes de Combate à Endemias.

O formulário de avaliação foi construído no Google Forms e era composto por questões fechadas, mapeadas na escala Likert [Likert 1932] de 5 itens, variando de -2 (discordo fortemente) até +2 (concordo fortemente), sendo o item central considerado indiferente (nem concordo e nem discordo). Nele, existiam 4 perguntas sobre informações pessoais (idade, nível de escolaridade, função e participação em treinamento para ACEs) e 16 questões, não obrigatórias, sobre a aplicação. Na Tabela 1 estão descritas as perguntas sobre a aplicação. O formulário ficou disponível no Google Forms para os ACEs do Zoonose do município de Lagarto/SE, durante a primeira quinzena do mês de fevereiro de 2017. Os avaliadores foram instruídos a utilizar o Zika Gamification por 30 minutos, no mínimo, antes de responderem o questionário.

Durante o experimento, a aplicação foi executada em um smartphone Samsung J5 Duos, com processador Quad Core 1.2 Ghz, 16GB de ROM, 1.5 GB de RAM e tela Super 
AMOLED de 5.0", suportando um resolução de 1280 x 720 pixels. O sistema operacional instalado no hardware era o Android 6 Marshmallow.

Para interpretação dos dados foi utilizada a frequência das respostas e a moda, que indica o item mais frequente, isso porque a escala Likert trabalha com dados ordinais. Em algumas análises as respostas de concordo parcialmente e fortemente foram agrupadas, a fim de analisar a frequência de participantes que concordavam com a afirmação.

\section{Discussão dos Resultados}

Antes da análise da aplicação é importante conhecer o perfil dos avaliadores, neste caso, os 17 ACEs que participaram do experimento. Na Figura 4 estão sumarizadas as principais informações sobre os agentes.
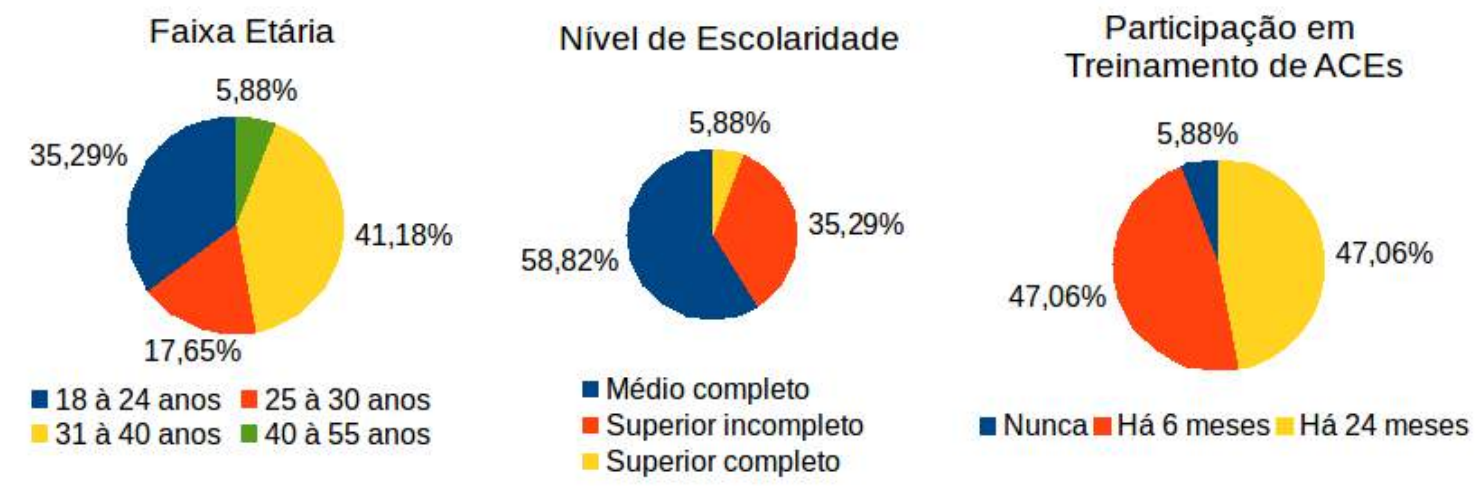

Figura 4. Informações dos entrevistados.

Conforme apresentado na Figura 4, durante o experimento, 94,12\% dos entrevistados estavam na faixa etária entre 18 e 40 anos, sendo que 35,29\% eram jovens de 18 à 24 anos e 41,18\% possuíam mais de 31 anos de idade. Este fato indica uma equipe heterogênea, constituída por jovens e adultos experientes. O nível de escolaridade é o mínimo exigido pelo cargo, uma vez que $94,12 \%$ possuíam nível médio, sendo que $35,29 \%$ buscaram melhorar o seu nível escolar, mas, ainda não concluíram o Ensino Superior.

Com relação a participação do treinamento para o cargo de Agente de Combate a Endemia, 47,06\% dos entrevistados participaram do treinamento recentemente, nos últimos 6 meses, enquanto outros 47,06\% cursaram nos últimos dois anos. Um dado preocupante neste quesito foi a informação de que um dos agentes nunca participou do treinamento, mesmo sendo requisito para execução das atividades do cargo, conforme demonstrado na Figura 4.

A análise dos aspectos técnicos e pedagógicos, bem como da opinião do aluno foi efetuada a partir dos dados apresentados na Tabela 1 e na Figura 5.

Com relação aos aspectos técnicos, $71,4 \%$ dos participantes julgaram os recursos midiáticos (som, imagem, vídeo) e colorido da interface adequados ao propósito, visto que $21,4 \%$ concordaram fortemente com esta afirmação (R1). Além disso, $53 \%$ dos entrevistados confirmaram a fluidez durante a execução do Zika Gamification (R2), ou seja, o software não apresentou lentidão ou "engasgos"durante o uso. O estudo dos aspectos técnicos demonstraram ainda que 2 entrevistados tiveram problemas ao "pausar", "parar" ou "voltar" a partida, embora 53\% discordem deste pensamento (R3). O interessante 
Tabela 1. Avaliação do Zika Gamification segundo modelo de [Rodrigues 2014]

\begin{tabular}{|c|c|c|c|c|c|c|c|}
\hline Aspectos & ID & Descrição & 2 & 1 & 0 & -1 & -2 \\
\hline Técnicos & R1 & $\begin{array}{l}\text { Existe no jogo equilíbrio entre os recursos de som, ani- } \\
\text { mação, cores,quantidade de informações e outras mídias. }\end{array}$ & 3 & 7 & 4 & 0 & 0 \\
\hline Técnicos & $\mathrm{R} 2$ & $\begin{array}{l}\text { O jogo apresenta sucesso de execução, como por exem- } \\
\text { plo: rápido carregamento e download, não apresenta tra- } \\
\text { vamento, entre outros. }\end{array}$ & 2 & 6 & 7 & 0 & 0 \\
\hline Técnicos & $\mathrm{R} 3$ & $\begin{array}{l}\text { É possível ao Agente "pausar", "parar" ou "voltar" uma } \\
\text { vez iniciada a partida. }\end{array}$ & 2 & 6 & 5 & 2 & 0 \\
\hline Pedagógicos & $\mathrm{R} 4$ & $\begin{array}{l}\text { O jogo trabalha aspectos necessários para atender o obje- } \\
\text { tivo proposto }\end{array}$ & 0 & 8 & 6 & 0 & 0 \\
\hline Pedagógicos & R5 & $\begin{array}{l}\text { No jogo são apresentadas situações que remetem a vida } \\
\text { cotidiana do Agente de Endemias ou contexto real. }\end{array}$ & 2 & 6 & 6 & 0 & 0 \\
\hline Pedagógicos & R6 & $\begin{array}{l}\text { Há possibilidade de interação entre os Agentes, como: } \\
\text { troca de experiência ou trabalho cooperativo. }\end{array}$ & 2 & 7 & 4 & 1 & 1 \\
\hline Pedagógicos & R7 & $\begin{array}{l}\text { Desperta o interesse do Agente pelo conteúdo trabalhado, } \\
\text { de forma inteligente e envolvente. }\end{array}$ & 1 & 7 & 6 & 0 & 0 \\
\hline Pedagógicos & $\mathrm{R} 8$ & $\begin{array}{l}\text { É desafiador, pois motiva o aluno a resolver as situações } \\
\text { propostas. }\end{array}$ & 3 & 6 & 5 & 0 & 0 \\
\hline Pedagógicos & R9 & $\begin{array}{l}\text { O jogo oportuniza a interação com o aluno, permitindo } \\
\text { ao mesmo explorar seus conhecimentos. }\end{array}$ & 2 & 9 & 4 & 0 & 0 \\
\hline Pedagógicos & $\mathrm{R} 10$ & $\begin{array}{l}\text { O jogo apresenta de modo adequado, um reforçador po- } \\
\text { sitivo para as respostas corretas. }\end{array}$ & 2 & 7 & 8 & 0 & 0 \\
\hline Pedagógicos & R11 & $\begin{array}{l}\text { As atividades são desenvolvidas de forma a aumentar gra- } \\
\text { dativamente as dificuldades e desafios propostos. }\end{array}$ & 1 & 9 & 5 & 0 & 0 \\
\hline Pedagógicos & R12 & $\begin{array}{l}\text { Quando o aluno erra o feedback do jogo é agradável, não } \\
\text { constrangedor. }\end{array}$ & 1 & 7 & 8 & 0 & 0 \\
\hline Opinião & R13 & Gostei da animação, das cores e do som que o jogo tem. & 3 & 9 & 3 & 0 & 0 \\
\hline Opinião & R14 & Achei o jogo interessante, pois teve desafios. & 1 & 10 & 4 & 0 & 0 \\
\hline Opinião & R15 & $\begin{array}{l}\text { Vou lembrar do que aprendi no jogo quando estiver exe- } \\
\text { cutando meu trabalho de agente. }\end{array}$ & 2 & 8 & 6 & 0 & 0 \\
\hline Opinião & R16 & Gostaria de jogar novamente este jogo. & 2 & 9 & 6 & 0 & 0 \\
\hline
\end{tabular}

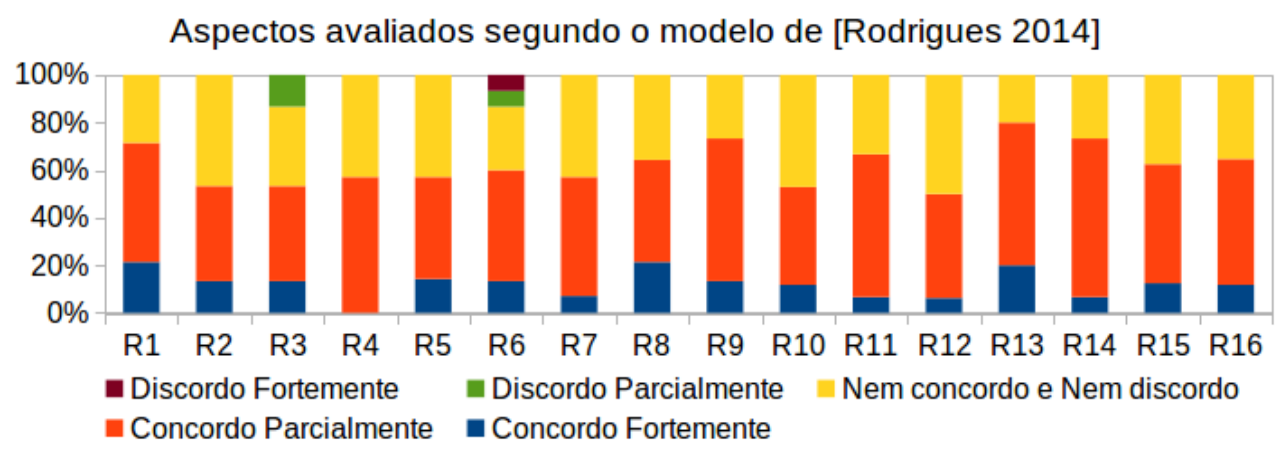

Figura 5. Sumarização dos resultados da avaliação.

neste caso é que o jogador pode realizar tais operações normalmente, exceto durante o processo de resposta de uma etapa. Logo, acredita-se que estes jogadores gostariam de interromper o progresso durante a etapa e continuar em seguida.

Sobre os aspectos pedagógicos, conforme apresentado na Tabela 1 e na Figura 5, $57,14 \%$ concordaram que a aplicação gamificada atingiu o objetivo proposto de auxiliar 
no aprendizado das atividades do cargo de ACEs (R4) e que despertou o interesse dos agentes pelo conteúdo trabalhado de forma inteligente e envolvente (R7). Além disso, 73,34\% dos entrevistados concordaram que o Zika Gamification permitiu explorar o conhecimento sobre o tema (R9), sendo que 57,14\% confirmaram que a aplicação apresentou situações que remetem ao cotidiano da prática de um agente (R5). Estes quesitos sugerem que o entrevistado se sentiu motivado e interessado a utilizar a aplicação para aprender ou relembrar o conteúdo de forma lúdica e divertida, ao invés de estudar exclusivamente através das apostilas do curso.

O Zika Gamification foi desafiador para 64,28\% dos participantes (R8), sendo que $66,67 \%$ concordaram que o grau de dificuldade aumentou gradativamente ao longo do tempo (R11). O uso de desafios ajustados ao nível do jogador e a evolução gradativa de dificuldade ajudam a prender a atenção no jogo e favorecerem o aprendizado, uma vez que os jogadores normalmente desistem quando encaram desafios muito difíceis, que os impedem de evoluir, ou quando encontram desafios muito fáceis, que os desestimulam ao longo do tempo por não desafiá-los.

Com relação ao feedback, 52,94\% afirmaram que a aplicação emitiu reforços positivos para respostas corretas (R10) e 50\% disseram que o feedback não foi constrangedor para os erros cometidos (R12). Analisar a qualidade do feedback é fundamental em uma aplicação com propósitos educacionais, pois a qualidade deste impacta na aprendizagem e pode desestimular o estudante, fazendo-o perder o interesse pelo assunto.

No quesito R6, que versa sobre troca de experiências ou trabalho cooperativo, esperava-se que os participantes discordassem da afirmação, uma vez que o Zika Gamification não implementa tal característica. Entretanto, inesperadamente, apenas 13,34\% dos entrevistados discordaram parcialmente ou fortemente da afirmação. Acredita-se que os ACEs confundiram a interação natural entre eles, motivada pelo entusiasmo da aplicação, com a possibilidade de interação oferecida pela aplicação. De qualquer forma, se a aplicação incentivou à troca de experiência ou o trabalho cooperativo há um ganho indireto no aprendizado e demonstra que tal característica deve ser adicionada futuramente.

Ressalte-se ainda que $80 \%$ dos ACEs gostaram das animações, das cores e dos sons da aplicação (R13) e 73,34\% acharam interessantes os desafios propostos (R14), sendo que 64,7\% jogariam novamente (R16). Agradar um público-alvo heterogêneo, constituído por pessoas de 18 a 55 anos, é muito difícil e, neste caso, observa-se que os participantes gostaram da aplicação e jogariam novamente. Logo, é possível que o Zika Gamification seja realmente utilizado pelos agentes, caso seja empregado e passe a fazer parte do módulo de treinamento do setor.

Outro dado importante é o fato de que $62,5 \%$ dos participantes afirmaram que lembrarão do que aprenderam com o Zika Gamification durante a execução das suas atividades práticas. Embora este resultado não seja preciso, por demonstrar apenas o sentimento dos ACEs sobre o fato de recordar futuramente do que foi estudado, aponta que eles acreditaram na proposta do treinamento gamificado e no aprendizado de forma lúdica.

De modo geral, conforme apresentado na Figura 6, 59,09\% dos participantes concordaram que os aspectos técnicos atendem ao propósito da aplicação, quando se trata de recursos midiáticos, fluidez da execução e possibilidade de parar e retormar o progresso, embora 4,55\% discordem parcialmente desta afirmação. Já nos aspectos pedagógicos, 


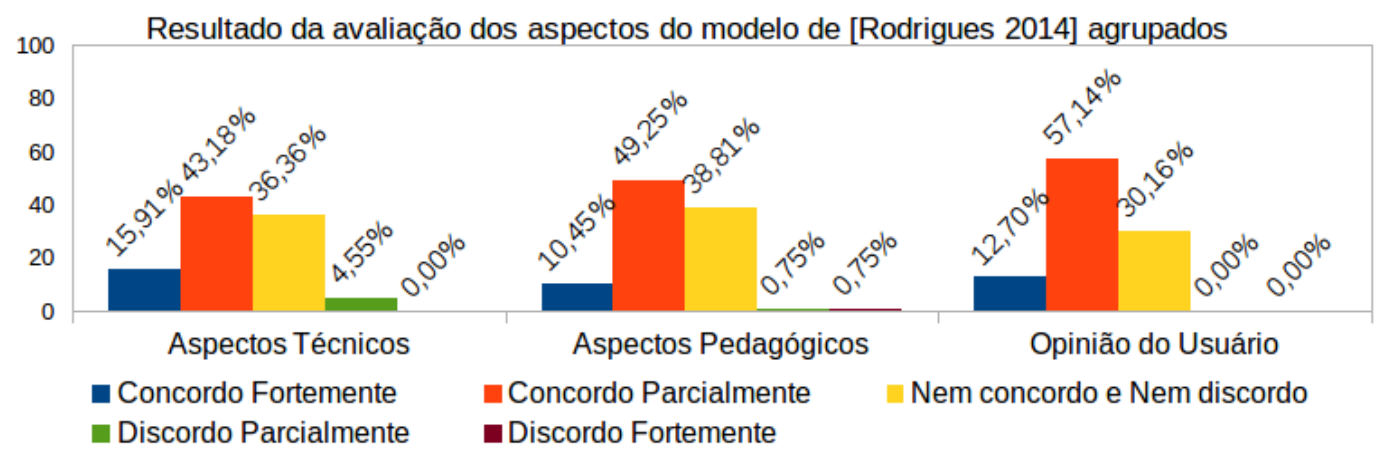

Figura 6. Resultado agrupado da avaliação.

$59,70 \%$ confirmaram que o objetivo educacional da aplicação, os conteúdos, os desafios e os feedbacks fornecidos foram adequados ao público-alvo. Na opinião geral, 69,84\% dos ACEs, afirmaram que o jogo vai ajudar a lembrar o conteúdo durante a execução da atividade, portanto, gostariam de jogar novamente.

Por fim, é importante destacar na Tabela 1 e na Figura 5 que somente o critério R6 obteve nota discordo parcialmente ou fortemente na avaliação, totalizando apenas 2 votos de um total de 241 , ou seja, menos de $1 \%$ dos votos. Este fato ressalta a importância da aplicação para o público-alvo e aponta indícios da sua qualidade.

\section{Considerações Finais}

Os Agentes de Combate à Endemias (ACEs) são os responsáveis por combater a proliferação do mosquito Aedes Aegypti, vistoriando os locais, aplicando larvicidas e inseticidas e orientando a comunidade quanto à prevenção de doenças como a Dengue, a Chikungunya e o Zika. Para obter sucesso no combate ao vetor é primordial que os ACEs se capacitem no curso de formação profissional definido pelo [Ministério da Saúde 2011]. Entretanto, os próprios agentes apontam a ineficiência na sua formação. Neste sentido, o artigo apresentou uma aplicação móvel gamificada, denominada Zika Gamification, para auxiliar no treinamento dos Agentes de Combate à Endemias do município de Lagarto/SE.

O Zika Gamification permite aos jogadores conhecer a história do Aedes Aegypti no Brasil, aprender sobre o mosquito e as doenças transmitidas por ele, entender as atribuições do ACEs, o LIRAa e o PNCD. A aplicação gamificada também motiva os jogadores a evoluírem no estudo, fornecendo feedback através de pontos, experiências e medalhas, além de estimular a competição entre os ACEs em busca do aprendizado, no qual todos evoluem, aprendem e vencem.

A aplicação foi avaliada por 17 ACEs do setor de Zoonose do município de Lagarto/SE e constatou-se que a interface e os recursos midiáticos da aplicação agradaram os agentes, não apresentando problemas de lentidão ou travamento durante o uso; que o jogo é desafiador e remete ao cotidiano da prática de um agente; e que eles lembrarão das lições aprendidas no jogo durante a execução das suas atividades práticas.

Embora o estudo realizado aponte fortes indícios de que o Zika Gamification atingiu o propósito de auxiliar no treinamento dos ACEs, é importante ressaltar a falta de um estudo controlado, com intuito de mensurar a capacidade de auxílio no aprendizado das atribuições do agente. Portanto, julga-se necessário realizar futuramente um estudo mais 
aprofundado, no qual será comparado o grupo de controle ao experimental para testar a hipótese.

Futuramente, pretende-se ainda: permitir que o jogador possa "pausar", "parar" ou "voltar" durante o processo de respostas de uma etapa; estudar e implantar mecanismos de feedback mais adequados aos ACEs, com intuito de melhorar a avaliação do jogo neste quesito e favorecer o aprendizado; incluir o sistema de troca de recompensas, a fim de motivar ainda mais a participação dos agentes; e adicionar recursos que possibilitem a troca de experiências ou o trabalho cooperativo no Zika Gamification.

\section{Referências}

[Fraga and Monteiro 2014] Fraga, L. d. S. and Monteiro, S. (2014). A gente é um passador de informação: práticas educativas de agentes de combate a endemias no serviço de controle de zoonoses em belo horizonte, mg. Saúde e Sociedade, 23(3):993-1006.

[Gladcheff 2001] Gladcheff, A. P. (2001). Um instrumento de avaliação da qualidade para software educacional de matemática. PhD thesis, Universidade de São Paulo.

[Kapp 2012] Kapp, K. M. (2012). The gamification of learning and instruction: gamebased methods and strategies for training and education. John Wiley \& Sons.

[Likert 1932] Likert, R. (1932). A technique for the measurement of attitudes. Archives of psychology.

[Ministério da Saúde 2011] Ministério da Saúde, B. (2011). Diretrizes e orientações para o programa de qualificação dos agentes de combate as endemias e demais agentes que atuam em vigilância em saúde. Technical report, Secretaria de Gestão do Trabalho e da Educação na Saúde. Departamento de Gestão da Educação na Saúde. Ministério da Saúde. Brasil.

[Oliveira et al. 2016] Oliveira, R., Moura, A., Barros, M., Cavalcante, A., and Junior, F. (2016). Gamificação e crowdsourcing no combate sustentável ao aedes aegypti. In Brazilian Symposium on Computers in Education (Simpósio Brasileiro de Informática na Educação-SBIE), volume 27, page 390.

[Oliveira Júnior et al. 2016] Oliveira Júnior, J. F., Tubelo, R. A., Gradella, G., and Machado, J. (2016). O design da informação aplicado ao desenvolvimento da interface gráfica de um jogo sério sobre o combate ao mosquito aedes aegypti. J Bras Tele, 4(2):246-254.

[Quintão 2016] Quintão, M. S. (2016). X-dengue: game design e estratégias de gamificação de um jogo educativo sobre a dengue.

[Rodrigues 2014] Rodrigues, G. C. F. S. (2014). Instrumento de avaliação de jogos eletrônicos educativos do ensino fundamental i. Master's thesis, Programa de Pós-Graduação em Linguística e Ensino do Centro de Ciências Humanas, Letras e Artes da Universidade Federal da Paraíba, Paraíba.

[Savi et al. 2011] Savi, R., Wangenheim, C., and Borgatto, A. (2011). Um modelo de avaliação de jogos educacionais na engenharia de software. Anais do XXV Simpósio Brasileiro de Engenharia de Software (SBES 2011), São Paulo.

[Torres 2009] Torres, R. (2009). Agente de combate a endemias. Revista Poli - Saúde, Educação e Trabalho, 3(1). 